\title{
Effects of radio-frequency radiation on the permeability of blood-brain barrier
}

\author{
Bahriye Sirav $^{1 *}$, Nesrin Seyhan ${ }^{1}$
}

\begin{abstract}
Health concerns have been a raised after the enormous increase in the use of mobile phones and related base stations throughout the world. In spite of extensive increase in the studies of biological effects of mobile phone radiations with in last decades, little is known about the effect of long term exposure. In this present report, we summarized a review of the literature on the effects of radio-frequency radiation exposure on the permeability of blood-brain barrier. Gazi University Biophysics group have earlier shown that the electromagnetic radiation emitted by mobile phones - also called radio-frequency radiation - alters the permeability of the blood-brain barrier, GSM like modulated fields were found to be more effective than continuous-wave fields. This paper will review some evidence that demonstrates the existence of non-thermal effects and the exposure complexities that must be considered and understood to provide appropriate, more thorough evaluation and guidance for future studies and for assessment of potential health consequences
\end{abstract}

Key Words: Permeability; Blood brain barrier; Radio Frequency Radiation; Mobile Phones

\section{Introduction}

For many years there has been a discussion among the general public regarding the biological effects of radio-frequency radiation (RFR) on the human organism. The mobile phone induced effects on the permeability of blood-brain barrier (BBB) is one of the main topics of importance for the whole society today. Electromagnetic spectrum (Figure 1) covers a broad frequency range; static electric and magnetic fields, low-frequency electric and magnetic fields and high-frequency electromagnetic fields that is also called radio-frequency radiation, infrared radiation (IR), visible light, ultraviolet radiation (UV), X-rays and Gamma Rays which includes $1022 \mathrm{~Hz}$ frequencies. The upper radiofrequency range $(\mathrm{GHz}$ range- tens/hundreds of $109 \mathrm{~Hz}$ ) includes microwaves. RFR does not have sufficient energy to produce ionization. It is universally accepted that RFR can cause tissue heating (thermal effects) and extremely low-frequency (ELF) fields, e.g., 50 and $60 \mathrm{~Hz}$, can cause electrical current flows that shock and even damage or destroy tissues (12). These factors alone are the underlying bases for present electromagnetic field exposure standards. The article reviews current research on biological effects of RFR on the permeability of blood-brain barrier..

\section{Overview}

Today more than half of the world's population owns mobile phones. For 2017, the number of mobile phone users is forecast to reach 4.77 billion. Lifelong exposure to the radio frequency radiations (RFR) from mobile phones, with start already at a young age, is becoming increasingly among the new generations of mobile phone users. The mobile phones are held in close proximity to the head, or with in a meter of the head when hands-free kits are used. The emitted radio-frequency radiation have been shown to have many effects upon the brain; e.g. alterations of cognitive functions (1), gene expression alterations in cerebellum (2), cortex and hippocampus (3), changes of neurotransmitter levels such as decrease of cholinergic activity (4), and effect on brain waves as determined by electroencephalography - EEG (5). Epidemiological studies also indicate that long term exposure increases the risk of not only acoustic neuroma (6), but also malignant glioblastoma multiform (7) for mobile phone use longer than 10 years. The WHO (World Health Organization) / International Agency for Research on Cancer (IARC) has classified RFR as possibly carcinogenic to humans (2B) based on the increased risk for glioma, a malignant type of brain cancer associated with wireless phone use (8).

Received 22-02-2016 Accepted 29-03-2016 Available Online 15-05-2016

1 Gaziantep University School of Medicine Dept. of Biophysics \& Gazi Non-Ionizing Radiation Protection Center, Ankara, Turkey

* Corresponding Author: Bahriye Sirav E-mail: bahriyes76@gmail.com 


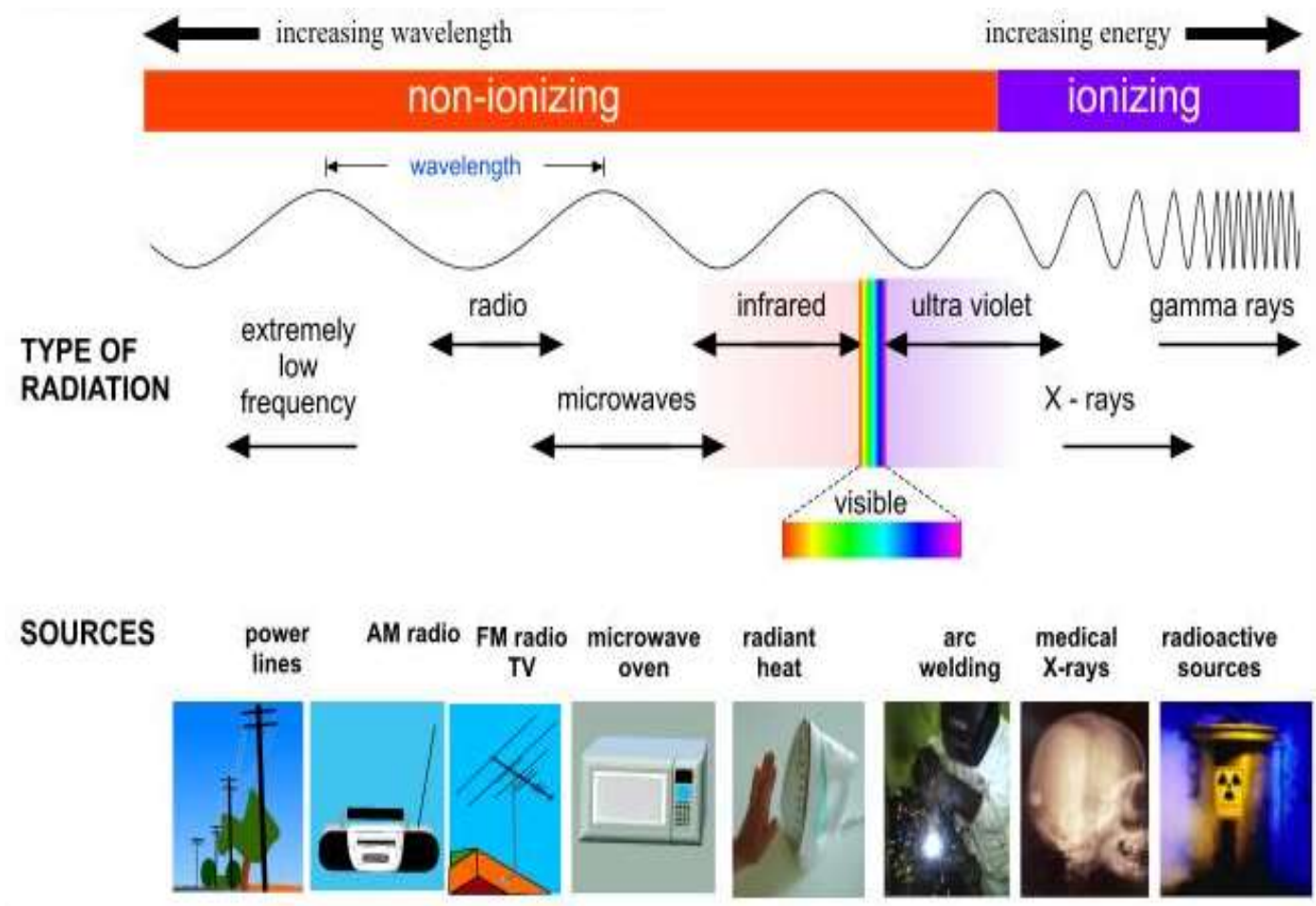

Figure 1. Electromagnetic Spectrum

IARC working group discussed one study of past mobile phone use (up to the year 2004), this study showed a $40 \%$ increased risk of gliomas in the highest category of heavy mobile phone users (Reported average: 30 minutes per day over a 10 year period).

It has been shown that RFR leads to increase in the permeability of the blood-brain barrier (BBB) (Figure 2) $(9-10)$.

The BBB is a hydrophobic barrier, formed by vascular endothelial cells of the capillaries in the brain, with tight junctions between these endothelial cells (11). It protects the mammalian brain from potentially harmful compounds in the blood. Perivascular structures such as astrocytes and pericytes as well as a bi-layered basal membrane also help maintaining the BBB. In the functioning BBB, the membrane properties control the bidirectional exchange between the general circulation and the central nervous system - CNS. Water, most lipid-soluble molecules, oxygen and carbon dioxide can diffuse from the blood to the nerve cells. The barrier is slightly permeable to ions such as sodium, potassium and chloride, but large molecules, such as proteins and most water-soluble chemicals pass poorly. However, when this barrier is damaged, in conditions such as tumors or infections, the normally excluded molecules can pass through, possibly bringing toxic molecules out into the brain tissue.
The selective permeability is disrupted temporally in cases of epileptic seizures (10). The result of this can be cerebral edema, increased intracranial pressure and irreversible brain damage. Also, toxic substances from the blood circulation now reach out to the neurons. Even transient openings of the BBB can lead to permanent tissue damage (11).

Many national and international exposure standards for RFR exposure from the use of mobile phone, related base stations, radars, other wireless devices, Wi-Fi systems etc. are ultimately based on the production of heat particularly in regions of the head, that is, thermal effects. The recent recommendations for limits of exposure to the general public for RFR (12) are set in order to avoid thermal effects upon the brain parenchyma. There are some reports that discuss the existence of non-thermal effects, and include provisions for reduced maximum-allowable limits should certain radiation characteristics occur during the exposure.

In the previous 1970s, when the radiation from radars and microwave ovens were considered to be possible health threats, the first studies on the microwave (MW) (in the GHz regions of RFR spectrum) effects upon the BBB were reported. Increased leakage of fluorescein after $30 \mathrm{~min}$ of pulsed and $\mathrm{CW}$ exposure (13) and passage of ${ }^{14} \mathrm{C}$-mannitol, inulin and dextran at very low energy levels (14) were reported. 


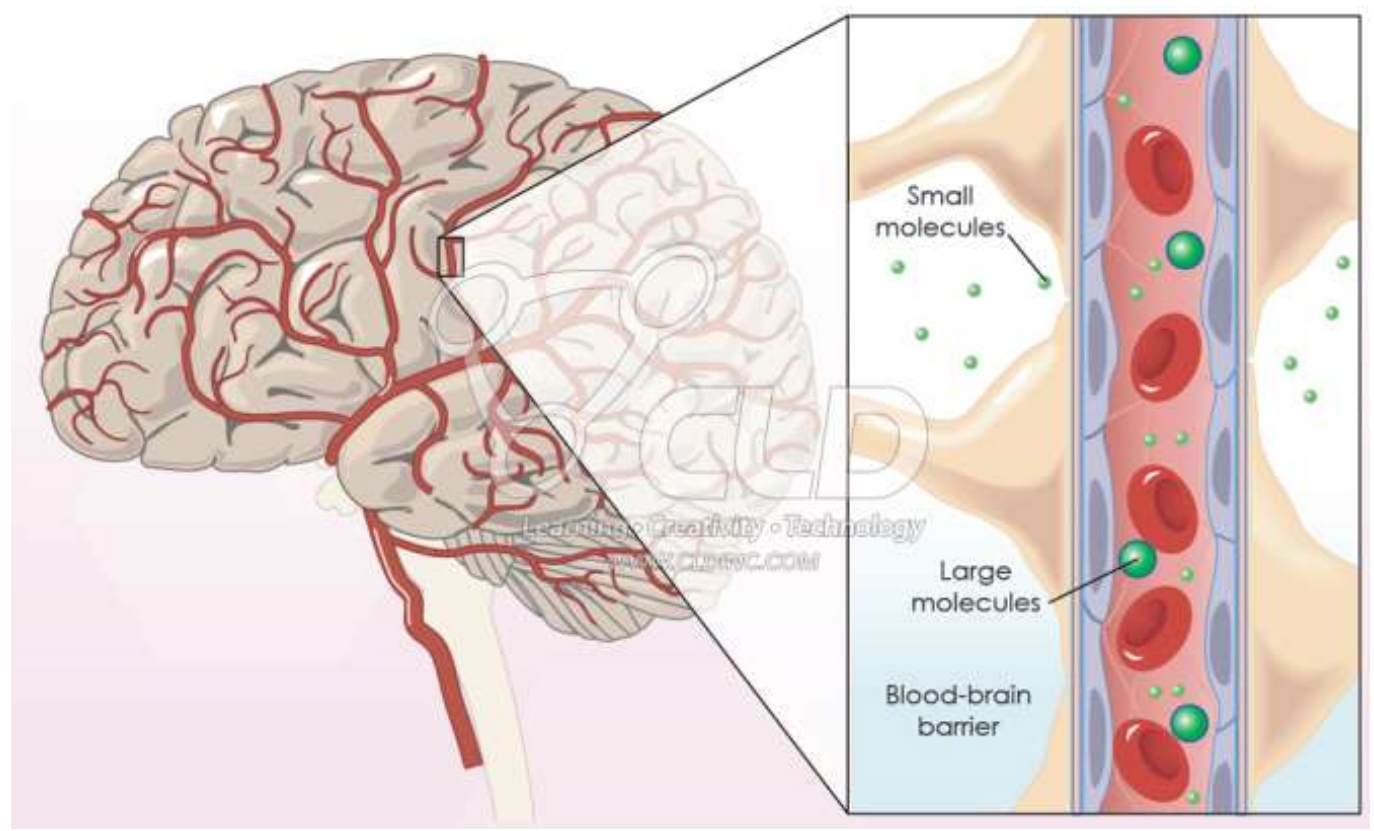

Figure 2: General structure of blood-brain barrier

The permeation of mannitol was found to be a definite function of exposure parameters such as power density, pulse width, and the number of pulses per second. Also, the BBB permeability depended on the time between RFR exposure and the sacrifice of the animals, with more pronounced effects seen in the animals sacrificed earlier after the RFR exposure. However, these results were not found in some replication studies (15). No induced BBB effects, was reported by Ward et al. (16) after exposure of rats to CWs at $2450 \mathrm{MHz}$; Ward and Ali (17) investigated the permeability of blood-brain barrier to high and low molecular weight compounds under $\mathrm{CW}$ and pulsedRFR. They exposed RFR on animals at $0.1 \mathrm{~W} / \mathrm{kg}$ SAR values and they found no change in uptake of either sucrose or inulin as compared with those of sham exposed animals. Gruenau et al. (18) exposed animals to pulsed or $\mathrm{CW}$ waves at $1.8 \mathrm{GHz}$ (including totally 31 rats) and found no effect about these exposures. On the other hand, Albert and Kerns (19) observed RFR induced BBB permeability after exposure at 2450 $\mathrm{MHz} \mathrm{CWs}$, with an increase in the number of pinocytotic vesicles among the irradiated animals. However, after a recovery time of $1-2 \mathrm{~h}$, the permeation was not detectable anymore.

In our previous studies we have seen that non-thermal $\mathrm{RF}$ fields cause significantly increased leakage through the BBB of exposed rats sacrificed immediately after the RFR exposure, as compared to sham exposed animals (20-22). We have used 900 $\mathrm{MHz}$ and $1800 \mathrm{MHz}$, continuous wave and global system for mobile communications (GSM) modulated RFR and found increased permeability of blood-brain barrier of both female and male rats in non-thermal levels. Eberhardt et al (2008) have shown that two hours of exposure to the radiation from a GSM phone at $915 \mathrm{MHz}$, at non-thermal specific absorption rates (SAR) values of $0.12 \mathrm{~mW} / \mathrm{kg}, 12 \mathrm{~mW} / \mathrm{kg}$ and 120 $\mathrm{mW} / \mathrm{kg}$, gives rise to focal albumin extravasation and albumin uptake into neurons also 14 days after exposure (23). Significant neuronal damage is present 28 days and 50 days after exposure (24), but not after 14 days. BBB permeability is also increased in connection to mobile phone exposure in experiments from other laboratories (25-26). The effects of exposure to MRI related fields upon the BBB permeability were also investigated. MRI includes an exposure to a high-intensity static field, a RF field and a time-varying magnetic field. Shivers et al. (27) observed that the EMF exposure of MRI procedure resulted in a temporarily increased BBB permeability in the brains of rats. A vesicle-mediated transport of horseradish peroxidase (HRP) took place through transendothelial channels. Replications of the initial findings by Shivers et al. (27) were made by Garber et al. (28), whereas Adzamli et al. (29) and Preston et al. (30) could not confirm the findings. In 1990, quantitative support of the findings by Shivers et al. (20) was presented by the same group.

The BBB permeability to DTPA (diethylenetriameninepentaacetic acid) increased in rats exposed to the MRI. A suggested mechanism explaining the increased permeability was a stimulation of endocytosis, made possible through the time-varying magnetic fields. Salford's studies repeated the findings of the Shiver \& Prato group; BBB permeability to albumin was increased after 
exposure to MRI radiation. The most significant effect was observed after exposure to the RF part of the MRI. There are also studies which demonstrated no BBB alterations under mobile phone exposure or MRI exposure (31-32).

Salford et al. found an increased BBB permeability immediately after $2 \mathrm{~h}$ of mobile phone exposure (33), and also after 14 days and 50 days. Repetitions of their findings of increased BBB permeability after mobile phone exposure have been made (34). Four hours of $900 \mathrm{MHz}$ exposure at brain $(0.3$ to $7.5 \mathrm{~W} / \mathrm{kg}$ ) resulted in significantly increased albumin extravasation both at the SAR-value of $7.5 \mathrm{~W} / \mathrm{kg}$, which is a thermal effect, but extravasation was seen also at $0.3 \mathrm{~W} / \mathrm{kg}$ and $1.3 \mathrm{~W} / \mathrm{kg}$ (35). Albumin extravasation was also seen in rats exposed for $2 \mathrm{~h}$ to GSM liked modulated $900 \mathrm{MHz}$ at non-thermal SARvalues of $0.12,0.5$ and $2 \mathrm{~W} / \mathrm{kg}$ using fluoresceinlabelled proteins. A marked BBB permeabilization was observed at SAR of $2 \mathrm{~W} / \mathrm{kg}$, permeabilization was also present around intracranial blood vessels at the lower SAR-value of $0.5 \mathrm{~W} / \mathrm{kg}$. However, the extravasation at $0.5 \mathrm{~W} / \mathrm{kg}$ was seen at a lesser extent as compared to that seen at $2 \mathrm{~W} / \mathrm{kg}$. Finnie et al. (36) exposed mice for $1 \mathrm{~h}$ daily to RFR with SAR value of $4 \mathrm{~W} / \mathrm{kg}$, which is above the ICNIRP limit (12).

In a further study by Finnie et al. (37) 207 mice were exposed for 104 weeks at SAR-values of $0.25-4$ $\mathrm{W} / \mathrm{kg}$. In both Finnie's studies, there was no effect on the BBB permeability. The same group also reported that the immature $\mathrm{BBB}$ was insensitive to mobile phone exposure, seen after GSM- 900 radiation exposure of pregnant mice from day 1 to day 19 of gestation (SAR of $4 \mathrm{~W} / \mathrm{kg}$, exposure for $60 \mathrm{~min}$ daily). No increased albumin extravasation was seen in the new-born mice immediately after parturition. Kumlin et al. (38) confirmed that $900 \mathrm{MHz}$ radiation have no effect on the BBB permeability of young rats. In vitro models have been increasingly applied to investigate the BBB in last years; in one of these, it was shown that $1.8 \mathrm{GHz}$ exposure increase the permeability to sucrose (39). After modifications of the BBB model to one with higher tightness, however, the same group could not replicate their initial findings (40). They concluded that their in vitro BBB model also did not alter its tightness or transport behavior under the exposure of RFR emitted like 3G mobile phones (41).

There are also some reports that investigated the neuronal damage in connection to mobile phone exposure. Eberhardt et al. have evaluated the occurrence of neuronal damage in animals surviving a longer period after the exposure. This neuronal damage is seen as condensed dark neurons. Dark neurons have been proposed to have three main characteristics (42): (a) irregular cellular outlines, (b) increased chromatin density in the nucleus and cytoplasm and (c) intensely and homogenously stained nucleus. The neuronal damage was significantly increased in the exposed rats as compared to the sham exposed controls twenty-eight days after $2 \mathrm{~h}$ of mobile phone exposure (23). There was also an increased occurrence of neuronal damage 50 days after the same kind of mobile phone exposure. In these studies, normal neurons have been shown to have increased uptake of albumin. In previous studies of this group, damaged neurons were seen in all locations, intermingled with normal neurons especially in the cortex, hippocampus and basal ganglia. The damaged neurons were often shrunken and dark staining, homogenized with loss of discernable internal cell structures. Dark neurons are reported in clinical and experimental neuropathology from living tissues, but not in autopsy material unless the post-mortem period is short.

This could indicate that the formation of dark neurons is an active process that requires living neurons and that these cells must be reasonably intact (43). Dark neurons occur not only after GSM exposure but also in connection to experimental ischemia, hypoglycemia (44) and epilepsy (45). A pharmacologic origin, such as depolarization related to tissue glutamate release in injury, could explain the pathogenetic mechanism for dark neurons in these cases, rather than the pressurederived mechanical origin. The formation of dark neurons can be prevented using pharmacologic forms of glutamate antagonism (42). Ilhan et al. have also reported dark neurons in connection to RFR exposure of rats for 7 days, $1 \mathrm{~h}$ daily (46). An increase of oxidative damage was also seen in the exposed rats as a significant increase in malondialdehyde (MDA) (an index for lipid peroxidation), nitric oxide (NO) levels, brain xanthine oxidase (XO) and adenosine deaminase (ADA) activities, as compared to the controls. The RFR induced increments of XO, ADA, MDA and NO were prevented with treatment of the anti-oxidant Gingko biloba. The anti-oxidant activity of Gingko biloba is attributed to its flavinoid glycosides, which are the active compounds in the leaves. The action of these flavinoids is to destroy free radicals, such as NO and lipid peroxide radicals. Also the formation of dark neurons was reported to be prevented when the rats had been treated with Gingko biloba.

It has been suggested that BBB leakage is the major reason for nerve cell injury, such as dark neurons in stroke-prone spontaneously hypertensive rats (47). Albumin leaks into the brain and neuronal degeneration is seen in areas with BBB disruption in several circumstances: after intra-carotid infusion of hyperosmolar solutions in rats; in the stroke prone hypertensive rat (48). The linkage between albumin extravasation over the BBB and neural damage might be a potentiating effect of albumin upon the glutamate-mediated neurotoxicity (11). Indeed, both albumin and glutamate induced lesions have the same histopathological appearance with invasion of 
macrophages and absence of neuronal cell bodies and axons in the lesion areas (49). The glutamate itself can also increase the BBB opening (50), leading to further albumin extravasation out into the brain parenchyma.

\section{Conclusion}

Scientific literature on the effects of RFR on bloodbrain barrier is reviewed. The controversy about potential health hazards associated with the exposure to RFR has been recently stimulated by the increasing use of mobile phones and related RFR sources. Attention has focused here on non-thermal effects of low-level RFR, which does not lead to a heating of tissue. At the present level of knowledge, there is no final comment that can be drawn from the available data concerning potential health hazards. Although there seem to be some biological effects, these cannot provide pure evidence for any adverse health consequences. However, further research is needed for a better understanding of the interaction between RFR and biological effects. In contrast to low-frequency fields, exposure to high-frequency non-ionizing radiation i.e. RFR can lead to significant absorption of energy and temperature increases, depending on the radiation intensity. Safety guidelines recommend upper intensity limits to prevent significant temperature rises. There is increasing evidence that weak RFR, at intensities well below those necessary to cause any significant heating, can also induce biological effects. Attention is now focused on these direct non-thermal effects of low-intensity RFR not mediated by heating of tissue. This holds particularly for the controversy regarding health consequences of the new communication technologies. Although there are an increasing number of reports about biological effects induced by weak RFR, there is still a great lack of available data, especially related with human beings. An important drawback is that the fundamental mechanisms of the interaction with biological systems are not yet understood in detail. Finally, efforts have to be made to elucidate the fundamental mechanisms underlying the interaction of RFR and the central nervous system on the neuronal level. Whereas the effects of high levels of RFR leading to tissue heating are basically understood, there is still a great lack of knowledge regarding the non-thermal effects of low intensity radiation.

Positive findings must be replicated by independent research groups, and interpretation of results must not be distorted due to potential conflicts of interests, because of funding administered by the communication industry or influences of specific interest groups. On the other hand, although negative findings do not necessarily confirm the absence of a potential biological effect, an accumulation of wellperformed studies producing negative results will provide increasing confidence regarding the safe use of mobile phones.
Conflict of Interest: The authors declare no potential conflicts of interest with respect to the research, authorship, and/or publication of this article.

Ethical issues: All Authors declare that Originality of research/article etc... and ethical approval of research, and responsibilities of research against local ethics commission are under the Authors responsibilities. The study was completed due to defined rules by the Local Ethics Commission guidelines and audits.

\section{References}

1. Nittby H, Grafström G, Tian D, Brun A, Persson BRR, Salford LG, Eberhardt J. 2008. Cognitive impairment in rats after long-term exposure to GSM-900 mobile phones. Bioelectromagnetics 29: 219-232.

2. Belyaev LY, Bauréus Koch C, Terenius O, RoxströmLindquist K, Malmgren LOG, Sommer WH, Salford LG, Persson BRR. 2006. Exposure of rat brain to $915 \mathrm{MHz}$ GSM microwaves induces changes in gene expression but not double stranded DNA breaks or effects on chromatin conformation. Bioelectromagnetics 27: 295-306.

3. Nittby H, Widegren B, Krogh M, Grafström G, Rehn G, Berlin H, Eberhardt JL, Malmgren L, Persson BRR, Salford LG. 2008. Exposure to radiation from global system for mobile communications at $1800 \mathrm{MHz}$ significantly changes gene expression in rat hippocampus and cortex. Environmentalist. (published online ahead of print 15 April 2008)

4. Lai H, Carino MA, Horita A, Guy AW. 1992. Opioid receptor subtypes that mediate a micro-wave induced decrease in central cholinergic activity in the rat, Bioelectromagnetics 13: 237-246.

5. Vecchio F, Babilono C, Ferreri F, Curcio G, Fini R, Del Percio C, Maria Rossini FP. 2007. Mobile phone emission modulated interhemisperic functional coupling of EEG alpha rhythms, Eur. J. Neurosci. 25: 1908-1913.

6. Hardell L, Carlberg M, Hansson Mild FK. 2005. Casecontrol study on cellular and cordless phones and the risk for acoustic neuroma or meningioma in patients diagnosed 2000-2003, Neuroepidemiology 25: 120-128.

7. Hardell L, Carlberg M, Hansson Mild K. 2006. Pooled analysis of two case-control studies on use of cellular and cordless phones and the risk for malignant brain tumours diagnosed in 1997-2003, Int. Arch. Occup. Environ. Health 79: 630-639.

International Agency for Research on Cancer, Radio Frequency Radiation Monograph http://monographs.iarc.fr/ENG/Monographs/vol102/

9. Nittby H, Grafström G, Eberhardt JL, Malmgren L, Brun A, Persson BRR, Salford LG. 2008. Radiofrequency and extremely low-frequency electromagnetic field effects on the blood-brain barrier, Electromagn. Biol. Med. 27: 103126.

10. Sirav B. 2008. $900 \mathrm{MHz}$ ve $1800 \mathrm{MHz}$ Radyo Frekans Radyasyonun Kan Beyin Bariyeri Geçirgenliğine Etkisi, Doktora Tezi (Danışmanı: Prof. Dr. Nesrin Seyhan), Gazi Üniversitesi Sağlık Bilimleri Enstitüsü, Ankara. 
11. Kandel ER, Schwartz JH, Jessel TM. 2000. Principles of Neural Science, McGraw Hill : 1288-1303.

12. ICNIRP. 1998. Guidelines for limiting exposure to timevarying electric, magnetic and electromagnetic fields (up to 300 GHz), Health Phys. 74: 494-522

13. Frey AH, Feld SR, Frey B. 1975. Neural function and behaviour: defining the relationship, Ann. NY. Acad. Sci. 247: 433-439.

14. Oscar KJ, Hawkins TD. 1977. Microwave alteration of the BBB system of rats, Brain Res. 126: 281-293.

15. Preston E, Vavasour RJ, Assenheim HM. 1979. Permeability of the BBB to mannitol in the rat following 2450MHz microwave irradiation, Brain Res. 174: 109117.

16. Ward TR, Elder JA, Long MD, Svendsgaard D. 1982 Measurement of BBB permeation in rats during exposure to $2450-\mathrm{MHz}$ microwaves, Bioelectromagnetics 3: 371383 .

17. Ward TR, Ali JS. 1985. BBB permeation in the rat during exposure to lowpower $1.7-\mathrm{GHz}$ microwave radiation, Bioelectromagnetics 6:131-143.

18. Gruenau SP, Oscar KJ, Folker MT, Rapoport SI. 1982. Absence of microwave effect on blood-brain-barrier permeability to [C-14]- labeled sucrose in the conscious rat, Exp. Neurol. 75: 299-307.

19. Albert EN, Kerns JM. 1981. Reversible microwave effects on the BBB, Brain Res. 230: 153-164.

20. Sirav B, Seyhan N. 2015. Effects of GSM modulated radiofrequency electromagnetic radiation on permeability of blood-brain barrier in male \& female rats. J Chem Neuroanat. doi: 10.1016/j.jchemneu.2015.12.010. [Epub ahead of print]

21. Sirav B, Seyhan N. 2011. Effects of radiofrequency radiation exposure on blood-brain barrier permeability in male and female rats. Electromagn Biol Med. 30(4):25360 .

22. Sirav B, Seyhan N. 2009. Blood-brain barrier disruption by continuous-wave radio frequency radiation. Electromagn Biol Med. 28(2):215-22.

23. Eberhardt JL, Persson BR, Brun AE, Salford LG Malmgren LO. 2008. Blood-brain barrier permeability and nerve cell damage in rat brain 14 and 28 days after exposure to microwaves from GSM mobile phones, Electromagn. Biol. Med. 27: 215-229.

24. Salford LG, Brun A, Eberhardt JL, Malmgren L, Persson BRR. 2003. Nerve cell damage in mammalian brain after exposure to microwaves from GSM mobile phones, Environ. Health. Perspect. 111: 881-883.

25. Töre F, Dulou PE, Haro E, Veyret B, Aubineau P. 2002 Effect of $2 \mathrm{~h}$ GSM-900 microwave exposures at 2.0, 0.5 and $0.12 \mathrm{~W} / \mathrm{kg}$ on plasma protein extravasation in rat brain and dura mater, in: Proceedings of the 24th Annual Meeting of the BEMS, pp. 61-62.

26. Neubauer C, Phelan AM, Kues H, Lange DG. 1990. Microwave irradiation of rats at $2.45 \mathrm{GHz}$ activates pinocytotic-like uptake of tracer by capillary endothelial cells of cerebral cortex, Bioelectromagnetics 11: 261-268.
27.

Shivers RR, Kavaliers M, Teskey GC, Prato FS, Pelletier RM. 1987. Magnetic resonance imaging temporarily alters BBB permeability in the rat, Neurosci. Lett. 76: 25-31.

28. Garber HJ, Oldendorf WH, Braun LD, Lufkin RB. 1989. MRI gradient fields increase brain mannitol space, Magn. Reson. Imag. 7: 605-610.

29. Adzamli IK, Jolesz EA, Blau M. 1989. An assessment of BBB integrity under MRI conditions: brain uptake of radiolabelled Gd-DTPA and In-DTPA-IgG, J. Nucl. Med. 30: 839-840.

30. Preston E, Buffler K, Haas N. 1989. Does magnetic resonance imaging compromise integrity of the BBB? Neurosci. Lett. 101: 46-50.

31. Prato FS, Frappier RH, Shivers RR, Kavaliers M, Zabel P, Drost D, Lee TY. 1990. Magnetic resonance imaging increases the $\mathrm{BBB}$ permeability to 153-gadolinium diethylenetriaminepentaacetic acid in rats, Brain Res. 523: 301-4.

32. Prato FS, Wills JM, Roger J, Frappier H, Drost DJ, Lee TY, Shivers RR, Zabel P. 1994. BBB permeability in rats is altered by exposure to magnetic fields associated with magnetic resonance imaging at $1.5 \mathrm{~T}$, Microsc. Res. Technol. 27: 528-534.

33. Salford LG, Brun A, Eberhardt J, Malmgren L, Persson BB. 1992. Electromagnetic field-induced permeability of the blood-brain barrier shown by immunohistochemical methods. Interaction mechanism of low-level electromagnetic fields, in: B. Nordén, C. Ramel (Eds.), Living Systems, Oxford University Press, Oxford, UK, pp. $251-258$.

34. Salford LG, Brun A, Eberhardt JL, Persson BRR. 1993. Permeability of the blood-brain-barrier induced by 915MHzelectromagnetic-radiation continuous wave and modulated at $8,16,50$ and $200 \mathrm{~Hz}$, Bioelectrochem. Bioenerg. 30: 293-301.

35. Fritze K, Sommer C. 1997. Effect of global system for mobile communication (GSM) microwave exposure on BBB permeability in rat, Acta Neuropathol. 94: 465-470.

36. Finnie JW, Blumbergs PC, Manavis J, Utteridge TD, Gebski V, Davies RA, Vernon-Roberts B, Kuchel TR. 2002. Effect of long-term mobile communication microwave exposure on vascular permeability in mouse brain, Pathology 34: 244-347.

37. Finnie JW, Blumbergs PC, Cai Z, Manavis J, Kuchel TR. 2006. Effect of mobile telephony on blood-brain barrier permeability in the fetal mouse brain, Pathology 38: 63-65.

38. Kumlin T, Livonen H, Miettinen P, Juvonen A, van Groen T, Paranen L, Pitkäaho R, Juutilainen J, Tanila H. 2007. Mobile phone radiation and the developing brain: behavioral and morphological effects in juvenile rats, Radiat. Res. 168: 471-479.

39. Schirmacher A, Winters S, Fischer S, Goeke J, Galla HJ, Kullnick U, Ringelstein EB, Stögbauer F. 2000. Electromagnetic fields $(1.8 \mathrm{GHz})$ increase the permeability to sucrose of the BBB in vitro, Bioelectromagnetics 21: $338-345$

40. Franke H, Ringelstein EB, Stögbauer F. 2005. Electromagnetic fields (GSM 1800) do not alter BBB permeability to sucrose in models in vitro with high barrier tightness, Bioelectromagnetics 26: 529-535. 
41. Franke H, Streckert J, Bitz A, Goeke J, Hansen V, Ringelstein EB, Nattkämper H, Galla HJ, Stögbauer F. 2005. Effects of universal mobile telecommunications system (UMTS) electromagnetic fields on the BBB in vitro, Radiat. Res. 164: 258-269.

42. Kherani ZS, Auer RN. 2008. Pharmacologic analysis of the mechanism of dark neuron production in cerebral cortex, Acta Neuropathol. 116: 447-452.

43. Kövesdi E, Pál J, Gallyas F. 2007. The fate of "dark" neurons produced by transient focal cerebral ischemia in a non-necrotic and non-excitotoxic environment: neurobiological aspects, Brain Res. 1147: 272-283.

44. Gallyas F, Csordás A, Schwarcz A, Mázló M. 2005. "Dark" (compacted) neurons may not die through the necrotic pathway, Exp. Brain Res. 160: 473-486.

45. Söderfeldt B, Kalimo H, Olsson Y, Siesjö BK. 1983. Bicucullineinduced epileptic brain injury. Transient and persistent cell changes in rat cerebral cortex in the early recovery period, Acta Neuropathol. 62: 87-95.
46.

Ilhan A, Gurel A, Armutcu F, Kamisli S, Iraz M, Akyol O, Ozen S. 2004. Gingko biloba prevents mobile phoneinduced oxidative stress in rat brain, Clin. Chim. Acta 340: 153-162.

47. Fredriksson K, Kalimo H, Norberg C, Johansson BB, Olsson Y. 1988. Nerve cell injury in the brain of strokeprone spontaneously hypertensive rats Acta Neuropathol. (Berl) 76: 227-237.

48. Salahuddin TS, Kalimo H, Johansson BB, Olsson Y. 1988. Observations on exsudation of fibronectin, fibrinogen and albumin in the brain after carotid infusion of hyperosmolar solutions. An immunohistochemical study in the rat indicating longlasting changes in the brain microenvironment and multifocal nerve cell injuries, Acta Neuropathol. (Berl) 76: 1-10.

49. Hassel B, Iversen EG, Fonnum F. 1994. Neurotoxicity of albumin in vivo, Neurosci. Lett. 167: 29-32.

50. Eimerl S, Scramm M. 1991. Acute glutamate toxicity in cultured cerebellar granule cells: agonist potency, effects of $\mathrm{pH}, \mathrm{Zn} 2+$ and the potentiation by serum albumin, Brain Res. 560: 282-290.

Copyright (C) 2014 The Author(s); This is an open-access article distributed under the terms of the Creative Commons Attribution License (http://creativecommons.org/licenses/by/4.0), which permits unrestricted use, distribution, and reproduction in any medium, provided the original work is properly cited. All Rights reserved by international journal of Medical Science and Discovery. 